\title{
An Automotive Engine Calibration System Using Microcomputer
}

\author{
KENZO WATANABE, MEMBER, IEEE, AND MEHMET TÜMER
}

\begin{abstract}
An automotive engine calibration system has been developed to aid in development and evaluation of a control algorithm for electronic spark advance. It consists of the programmer, controller, and measurement units. Given the spark advance and the dwell time in the form of function subroutines written in BASIC, the programmer unit makes the advance and dwell tables as a function of engine speed and load. Referring to these tables, the controller unit operates the engine under calibration. The measurement unit measures the resultant engine performance and anlayzes the control algorithm. This process is repeated until the optimum algorithm is reached. A few test examples are also presented to demonstrate the system capability. This system features an easy operation and an accurate calibration.
\end{abstract}

\section{INTRODUCTION}

$\mathbf{U}^{2}$ P TO A DECADE ago, the basic objective for gasoline engine manufacturers was to produce good driveability and specific power output without much regard to fuel consumption. This situation has changed drastically in the last ten years, because exhaust emission legislation and fuel economy regulations have been introduced [1]. Ironically, emission control and fuel economy oppose each other. A good fuel economy engine requires a high octane fuel and a high compression ratio, but this results in the increased emission of nitrogen oxides and lead.

The engine performance depends largely on the spark timing. Therefore, its precise control is very effective for the optimization of the fuel economy, the exhaust emission, and the driveability [2]. This approach has led to the development of many electronic engine control systems such as SCC of Chrysler [3], EEC of Ford [4], MISAR of GM [5], ECCS of Nissan [6], and TCCS of Toyota [7].

The development of these control systems requires a prior establishment of the control algorithm for each engine. It is, however, very difficult to define the optimum spark timing theoretically because it is a complicated function of many engine parameters such as the mechanization, load, speed, air/ fuel ratio, temperature, and so on. Therefore, the determination of the optimum spark timing has been possible only by experiments which measure the engine performance as a function of only one parameter while keeping the others constant. This process, called the engine calibration, is thus a laborious, time-consuming, and tedious task. To alleviate this difficulty, a

Manuscript received April 15, 1983; revised January 16, 1984. This paper was presented at the 32 nd Annual Vehicular Technology Society Conference, San Diego, CA, May 23-26, 1982.

$\mathrm{K}$. Watanabe is with the Research Institute of Electronics, Shizuoka University, Hamamatsu 432, Japan. Telephone (01181) 0534-71-11'71.

M. Tümer was with the Research Institute of Electronics, Shizuoka University. He is now with MEGA Corporation, Ankara, Turkey. development system that allows quick calibration with a minimum design effort has been highly desired.

The first such system has been reported by Schlax and Auman [8]. They have used two computers, one for the operator interface and the other for the automobile control. Interfacing with the sensors installed on a vehicle and then referring to the control algorithm stored in programmable readonly memory (PROM), the automobile control computer determined the spark timing of the engine under test. This system was useful for the on-vehicle calibration, but its operation required detailed knowledge of electronic and computer technologies. Power, Winterbone, and Richards have proposed a simpler system using Intel 8080A microprocessor [9]. Their system has been useful for parameter optimization, but it could not emulate all the engine states.

The dominant parameters for determining the spark timing are the engine speed and load (manifold pressure) [10]. The optimum spark timing can then be approximated by a piecewise linear or quadratic function of the engine speed. Based on this concept, an automotive engine calibration system has been developed permitting easy operation and accurate calibration. This paper describes its principles of operation and demonstrates its capability by presenting a few test examples.

\section{DESIGN STRATEGY}

The spark timing is described in terms of the crank-angle (CA) with reference to the top dead center (TDC) of a compression stroke. This timing is usually within a few tens of degree before TDC and, hence, it is referred to as the advance angle or, for short, advance. The engine calibration is then the process to find the optimum advance as a function of the engine speed and load. The design strategy of the present system is to make it possible to calibrate the engine under not only constant but also variable engine speed and thereby to allow rapid calibration. This requires monitoring both the engine speed and the advance control for every engine revolution. Hence, $3 / 4$ period of one revolution is devoted to the engine speed detection and $1 / 4$ period remained to the advance control. The maximum advance is then limited to $90^{\circ} \mathrm{CA}$ before TDC, but this is sufficient for most automobile engines.

The dwell is another important parameter, indicating the energized period of the ignition coil. In a fully transistorized ignition system, dwell should also be controlled as a function of the engine speed to assure the spark ignition without destroying an ignitor transistor. Hence, a half-period of a revolution is devoted to the speed detection and the other half to the dwell control.

The timing diagram of the advance and dwell control is then 
given as shown in Fig. 1. The crank-angle involved in this diagram is determined by means of the crankshaft position sensor. Referring to Fig. 1, the advance and dwell control algorithm can be established in the following sequence:

1) detect engine speed;

2) load the appropriate advance and dwell data from the tables stored in random access memory (RAM) into the down-counters;

3) apply the advance and dwell control by decrementing the down-counters using the position signal which indexes the crankshaft position.

Modern vehicles require the advance to be controlled with an accuracy better than $1^{\circ} \mathrm{CA}$. Thus, the accuracy of the advance control in this system is specified as $0.1^{\circ} \mathrm{CA}$, while that of the dwell control is $0.2 \mathrm{~ms}$. These specifications impose the following accuracy on the speed detection. Assuming that the advance is a continuous and piecewise linear function of the engine speed, the error in the speed detection should be less than 1 percent in order to meet the specified advance accuracy. In the dwell control, it should be less than 10 percent. These requirements then specify the frequency $f_{c}$ of the clock signal and the bit capacity $N$ of the counter when the engine speed is detected by counting the clock signal using the counter;

$$
\epsilon \leq \frac{R_{\max }}{60 k f_{c}}, \quad 2^{N} \geq \frac{60 k f_{c}}{R_{\min }} .
$$

Here, $\epsilon$ is the error and $k$, the fraction of a period where the speed detection is made, is $3 / 4$ for the advance control and $1 / 2$ for the dwell control. $R_{\max }$ and $R_{\min }$ are the highest and the lowest engine speeds in $\mathrm{r} / \mathrm{min}$, respectively. $R_{\max }$ is assumed here to be $10000 \mathrm{r} / \mathrm{min}$. For the speed detection in the advance control, $f_{c}$ and $N$ are chosen to $31.25 \mathrm{kHz}$ and 12 , respectively. Then, the error is less than 0.71 percent and the $R_{\min }$ detectable without causing the counter overflow is $343 \mathrm{r} / \mathrm{min}$. The $f_{c}$ and $N$ for the dwell control are chosen to $3.9 \mathrm{kHz}$ and 8 , respectively. The error is then less than 8.5 percent and the $R_{\min }$ is 460 $\mathrm{r} / \mathrm{min}$. The overall system has been designed to accommodate these values.

\section{SYSTEM DESCRIPTION}

The block diagram of the automotive engine calibration system is shown in Fig. 2. It consists of the programmer, controller, and measurement units. The details of each unit will be given next.

\section{A. Programmer Unit}

A general purpose microcomputer has been used for the programmer unit permitting easy operation. First, a tentative advance is defined as a function of the engine speed and load. Using the function subroutines of BASIC, these functions are inputted to the microcomputer through a keyboard. According to these functions, the microcomputer constructs the advance dwell tables in the memory.

The flowchart for making the advance table is shown in Fig. 3(a). In this flowchart, $L$ is the engine load defined by the operator and $C$ is the address of memory into which the advance is stored. First, using the function subroutine

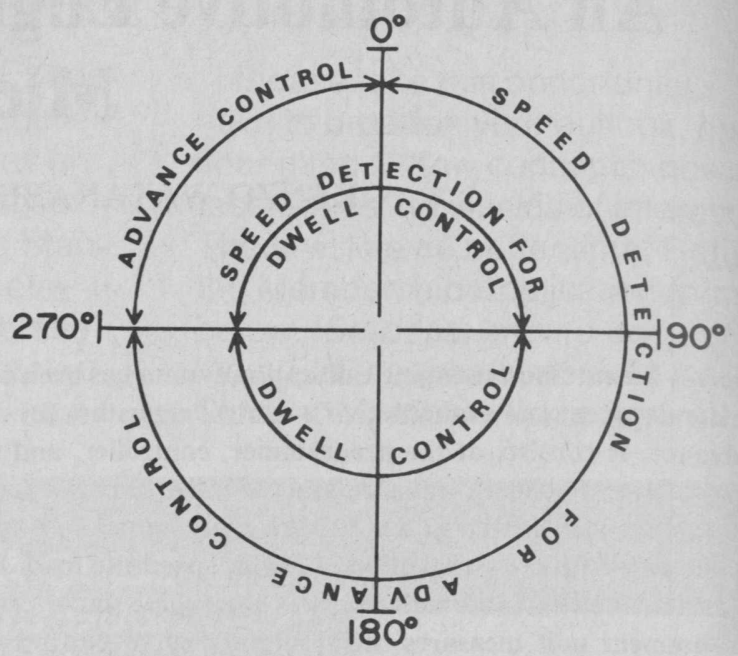

Fig. 1. The timing diagram of the advance and dwell control.

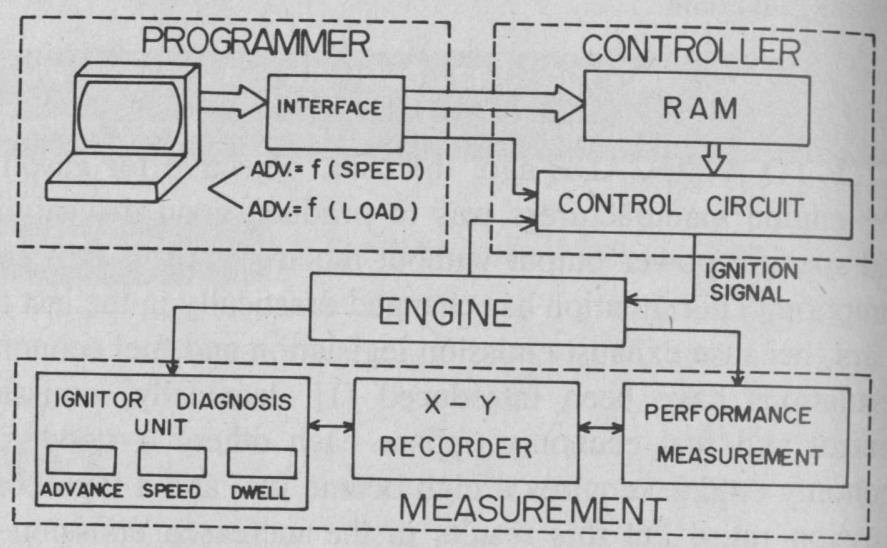

Fig. 2. The block diagram of the automotive engine calibration system.
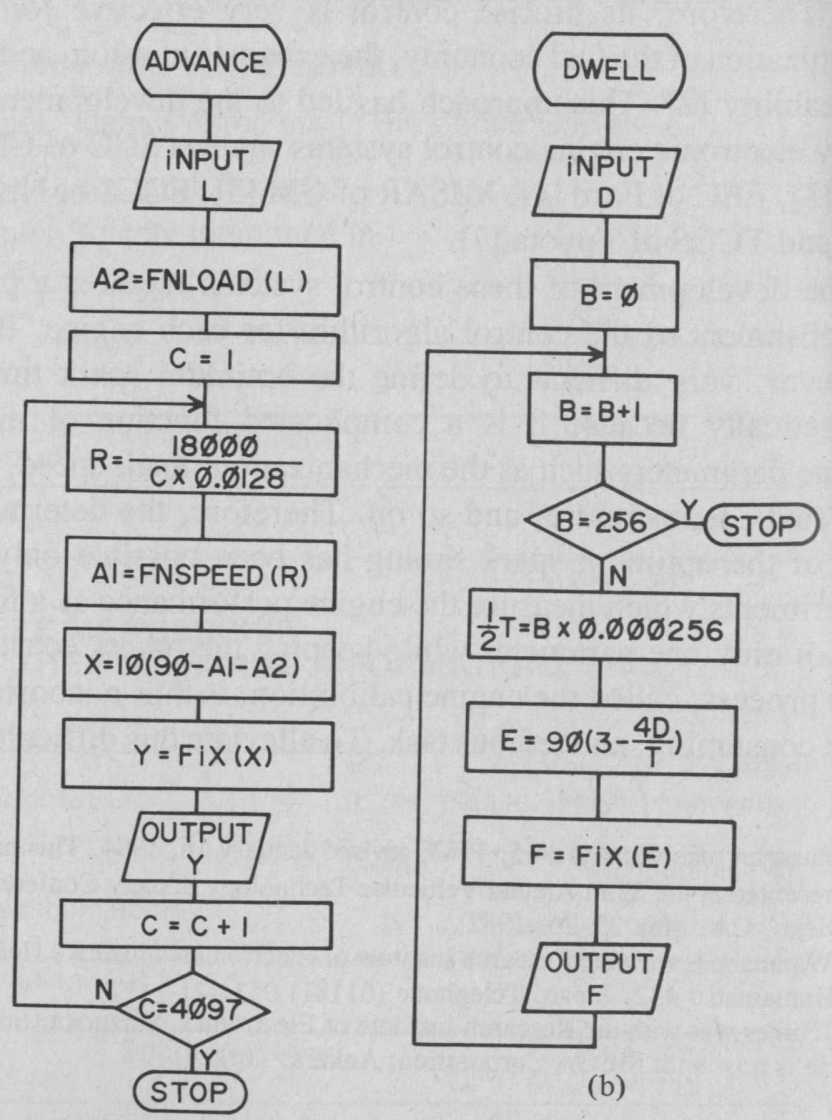

(b)

(a)

Fig. 3. Flowcharts for making (a) the advance table and (b) the dwell table 
FNLOAD $(L)$, the program calculates the advance $A 2$ as a function of the engine load. The advance table is indexed by the engine speed. Therefore, the address $C$ should be compatible with the engine speed detection. As described in the last section, the engine speed for the advance control is detected by the 12-bit address counter which counts $31.25 \mathrm{kHz}(32 \mu \mathrm{s}$ period) clock signal during $3 / 4$ period of revolution. The engine speed $R(\mathrm{r} / \mathrm{min})$ is thus related to the address $C$ as

$$
R=\frac{180}{128 \times 10^{-6} C}
$$

After converting the memory address into the engine speed, the program calculates the advance $A 1$ as a function of the engine speed $R$ using the function subroutine $\operatorname{FNSPEED}(R)$. The sum of $A 1$ and $A 2$ is the overall advance when the engine is running at the speed $R$ with the load $L$. Since the real-time advance control starts at $90^{\circ}$ before TDC, as shown in the timing diagram of Fig. 1, the advance should be obtained by the down-count starting from 90 . The crank-angle to be downcounted is then $90^{\circ}-(A 1+A 2)$. The $0.1^{\circ} \mathrm{CA}$ accuracy in advance control requires the angle to be decremented for every $0.1^{\circ}$. The count $Y$ to be decremented to zero is thus

$$
Y=\text { FIX }[10(90-A 1-A 2)] \text {. }
$$

The hardware used for the down-count consists of binary coded decimal (BCD) counters, as will be described in the next section. Therefore, converting $Y$ into a three-digit BCD form, in which the first two digits are integer part and the last significant digit (LSD) is the decimal part of the advance, the program stores it in the memory of address $C$. This process is repeated $2^{12}(=4096)$ times, until the advance table is completed.

The flowchart for making the dwell table is shown in Fig. 3(b). The dwell time $D$ depends on the ignitor used for the calibration. Therefore, the operator should first specify it. The program converts it to the dwell angle and stores it into the memory of address $B$. Since the dwell angle is also a function of the engine speed, the dwell table is indexed by the engine speed either. In the dwell control, the eight-bit address counter detects the engine speed by counting $3.9 \mathrm{kHz}$ ( $256 \mu$ s period) clock signal during a half-period of a revolution. Thus, the period $T$ of an engine revolution is related to the address $B$ as

$$
(1 / 2) T=256 \times 10^{-6} B \text {. }
$$

The dwell angle is $360 D / T$. The real-time dwell control starts at $270^{\circ}$ before TDC, as shown in Fig. 1, by down-counting the crank angle. The angle to be down-counted is then 270$360^{\circ} \mathrm{D} / T$. The $0.2 \mathrm{~ms}$ accuracy in dwell control can be attained by decrementing the angle for every $1^{\circ} \mathrm{CA}$. The count $F$ to be decremented to zero is thus

$$
F=\text { FIX }[90(3-4 D / T)] \text {. }
$$

The maximum permissible count is 180 , because the dwell control terminates at $90^{\circ}$ before TDC. Therefore, if $F$ is larger than 180 , then the program fixes it to 180 .

The hardware used for the down-count is an eight-bit binary counter. Hence $F$ is stored into the memory of address $B$ in a binary form. The program repeats the above process $2^{8}(=256)$ times, until it completes the dwell table.

Upon constructing the advance and dwell tables, the microcomputer sends them to the controller unit through the interface circuit. This approach allows for an operator to refine the control algorithm easily. The required operation is only to change the function subroutines.

\section{B. Controller Unit}

The block diagram of the controller unit is shown in Fig. 4. It is composed of two parts; the left half for controlling the advance and the right half for controlling the dwell. Each part consists of hard-wired logic circuits, including the multiplexer for selecting the clock signal, the address counter (12-bit for the advance table and eight-bit for the dwell table), the RAM for storing the table ( $4 \mathrm{~kW}$ with $1 \mathrm{~W}$ of 12 bits for the advance and 256 bytes for the dwell), and the down-counter for generating the ignition signal.

Prior to the engine operation, the advance and dwell tables are transferred from the memory in the microcomputer to the RAM's in the controller unit. The advance table is transferred when the transfer-enable signal SPROGRAM is true. The multiplexer MUX then selects the clock signal SCLK. Counting the SCLK, the 12-bit address counter generates the address signal to RAM. The advance data $Y$ sent from the microcomputer via three-state buffers are then written into the addressed RAM. This loading operation is repeated by incrementing the address, until the table transfer is completed. Then, the CSRST signal resets the address counter. The dwell table is also transferred by the same procedure when the DPROGRAM is true. In the transfer operation, the RAM is accessed only by the microcomputer and all the signals involved are generated by the software.

The controller unit under the engine operation is controlled by the signals shown in Fig. 5. The position signal informs the unit of the crankshaft position for every $1^{\circ} \mathrm{CA}$. The reference signal indexes the TDC of the cranshaft. These two signals are obtained by the crankshaft position sensor consisting of two optical couplers and a disk having 180 holes on its circumference. The $S$ - and $D$-LOAD signals indicate the instants when the advance data and the dwell data should be loaded into the downcounters, respectively. The $S$ - and $D$-HOLD signals enable the controller unit to discriminate between the speed detection and control periods. These four signals are generated by dividing the position signal using hardware counters.

Besides these signals, the angle signal is used to obtain $0.1^{\circ}$ CA accuracy in the advance control. It is generated by the digital frequency multiplier shown in Fig. 6. The modulo-2700 counter in the circuit divides $10 \mathrm{MHz}$ clock signal during $3 T / 4$, where $T$ is the period of an engine revolution. The ratio stored in the up-counter amounts to $10^{7} T / 3600$. This value is loaded into the presettable down-counter and used for the divisor to divide the same clock signal during the following $T / 4$. The ratio is then the angle signal which has the period $T / 3600$ (= $\left.0.1^{\circ} \mathrm{CA}\right)$.

The real-time control of advance and dwell is accomplished as follows: The eight-bit address counter in Fig. 4 counts 3.9 $\mathrm{kHz}$ clock signal while the DHOLD is true. This detects the engine speed for the dwell control and produces the address $B$ of the dwell table. The dwell data $F$ in the addressed RAM are 


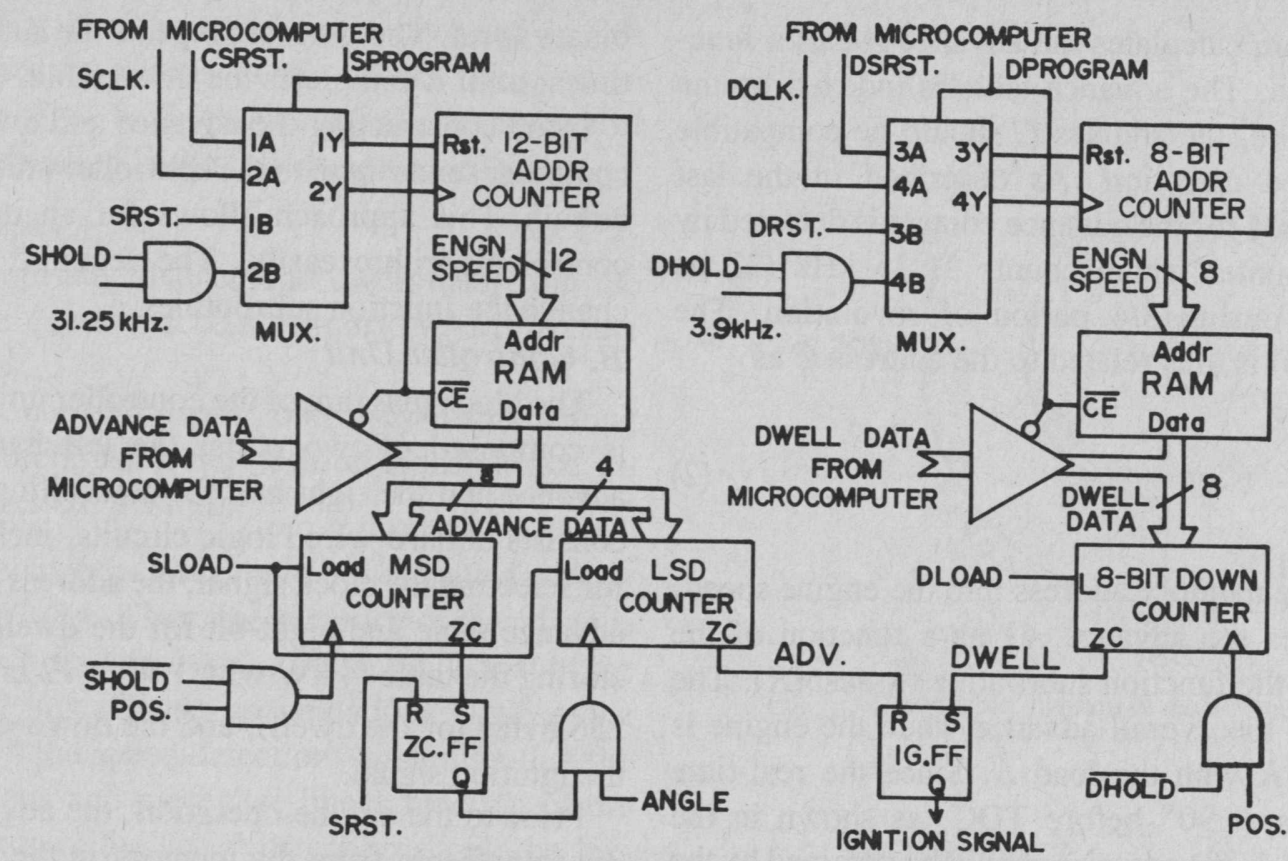

Fig. 4. The schematic diagram of the controller unit.

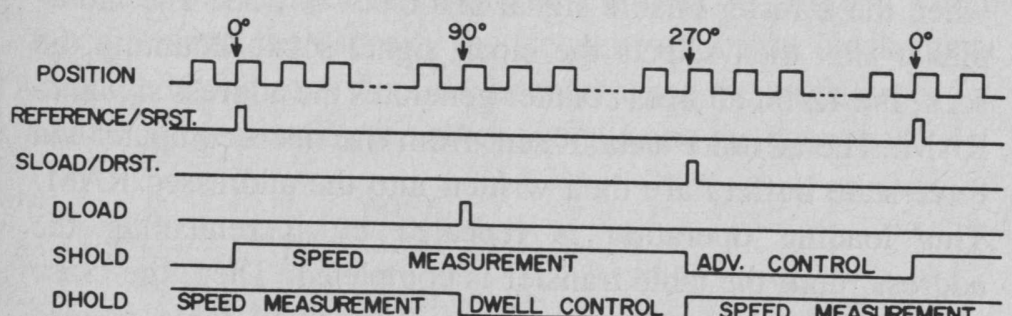

Fig. 5. Timing sequence of the digital signals controlling the controller unit.

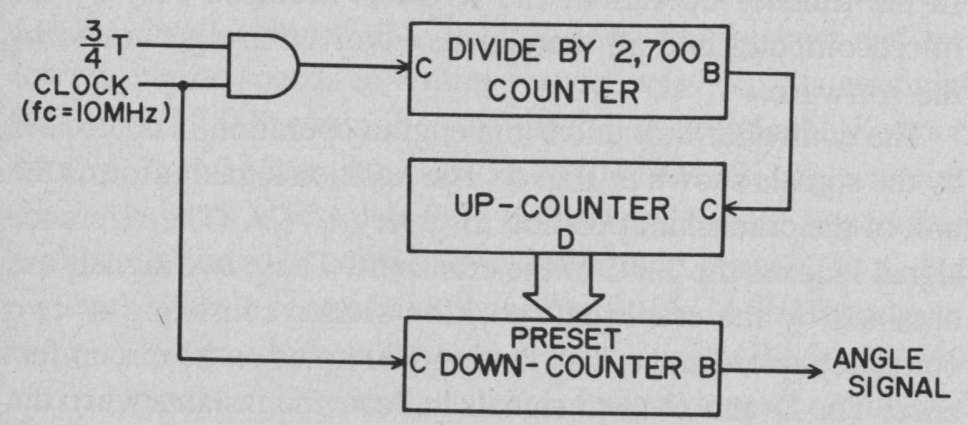

Fig. 6. The digital frequency multiplier for generating the angle signal.

loaded into the eight-bit down-counter when the DLOAD is true and decremented by the position signal to zero while the DHOLD is false. The zero-count $\mathrm{ZC}$ signal then sets the ignition flipflop IG $\cdot F F$ to turn the ignitor on.

Concurrently with the dwell control, the 12-bit address counter counts $31.25 \mathrm{kHz}$ clock signal while the SHOLD is true, producing the address $C$ of the advance table. The advance data $Y$ stored in the three-digit BCD form in the addressed RAM are loaded into the BCD down-counter, the first two digits into the most significant digit (MSD) and the LSD into the LSD counters, when the SLOAD is true. The MSD counter is then decremented by the position signal to zero while the SHOLD is false. The zero-count signal sets the ZC·FF, enabling the LSD counter to be decremented by the angle signal. The $\mathrm{ZC}$ signal from the LSD counter resets the IG ·FF to turn the ignitor off, causing the spark ignition. This method of determining the spark timing prevents the cumulative error which would be otherwise caused by using only the angle signal for down- counting, thereby allowing the precise control of the advance. The DRST and SRST signals reset the address counters to start a new cycle of operation.

\section{Measurement Unit}

This unit consists of the performance measurement and ignitor diagnosis subunits. The former measures and records the engine performance such as the output power, the fuel consumption, and the exhaust emission, using the conventional instruments. These results are used to analyze the engine control algorithm. If the revision is required, then the revised algorithm is again inputted to the programmer unit in the form of function subroutines. This process is repeated, until the optimum algorithm can be obtained.

The ignitor diagnosis unit measures the advance and the dwell of the ignitor to monitor the operation of controller unit. Developed as a stand-alone instrument, this unit has been described in detail in [11] and [12].

\section{TEST EXAMPLES}

The advances of typical motorcycle engines have been emulated to demonstrate the system capability. A fully transistorized ignitor was used for this experiment. The dwell time was specified as $3.5 \mathrm{~ms}$. Fig. 7 shows the advance of a fourcycle engine as a function of the engine speed and load. The function subroutines describing these characteristics are given in Fig. 9. These are inputted to the programmer unit to construct the advance table in the RAM of the controller unit. The actually controlled advance is then measured by the ignitor diagnosis unit. The data obtained under $0.8 \mathrm{load} /$ load $_{\max }$ condition are shown by circles in Fig. 7. The deviation between the programmed and measured advances is less than $0.2^{\circ}$. The accuracy of the ignitor diagnosis unit in the advance measurement is $0.1^{\circ}$ [12]. Therefore, the controller unit is deduced to control the advance with $0.1^{\circ} \mathrm{CA}$ accuracy.

The advance of a two-cycle engine takes in general a more complex form than that of a four-cycle engine. A typical advance is shown in Fig. 8. This advance curve was approxi- 


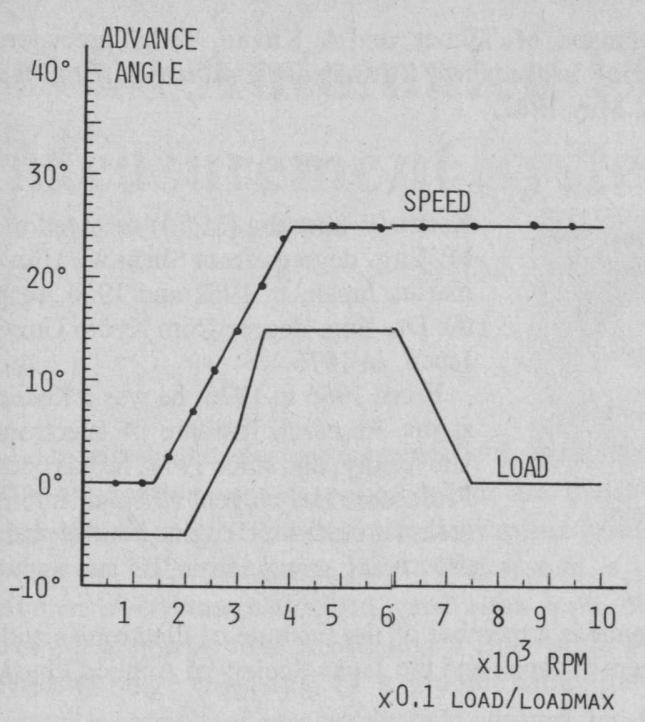

Fig. 7. The advance of a four-cycle engine.

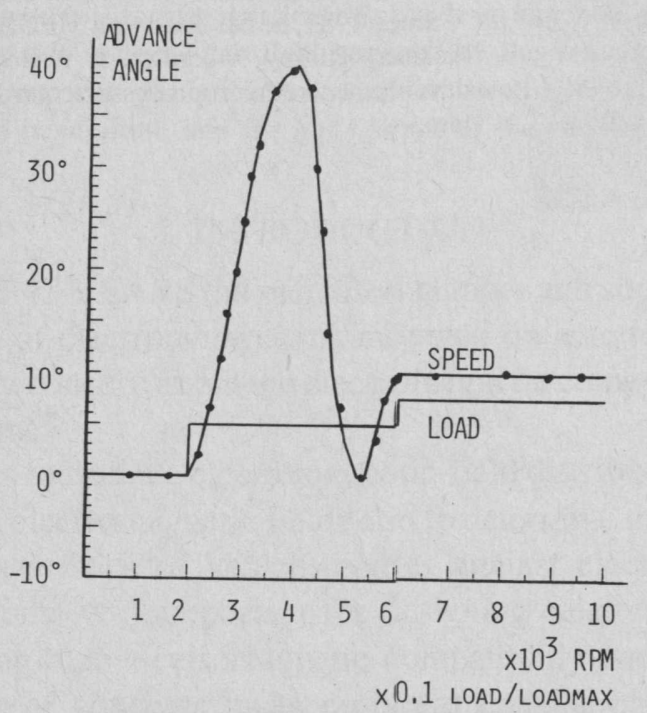

Fig. 8. The advance of a two-cycle engine.

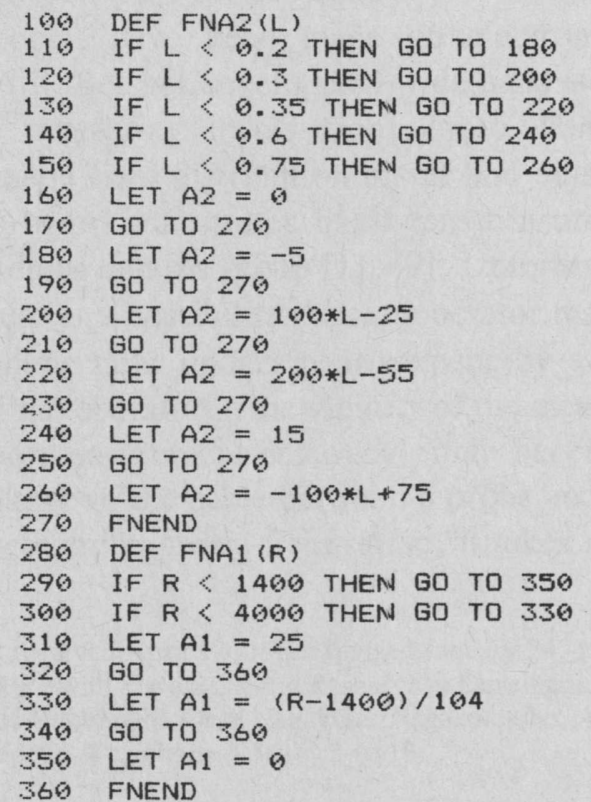

ig. 9. The function subroutine describing the advance shown in Fig. 7.

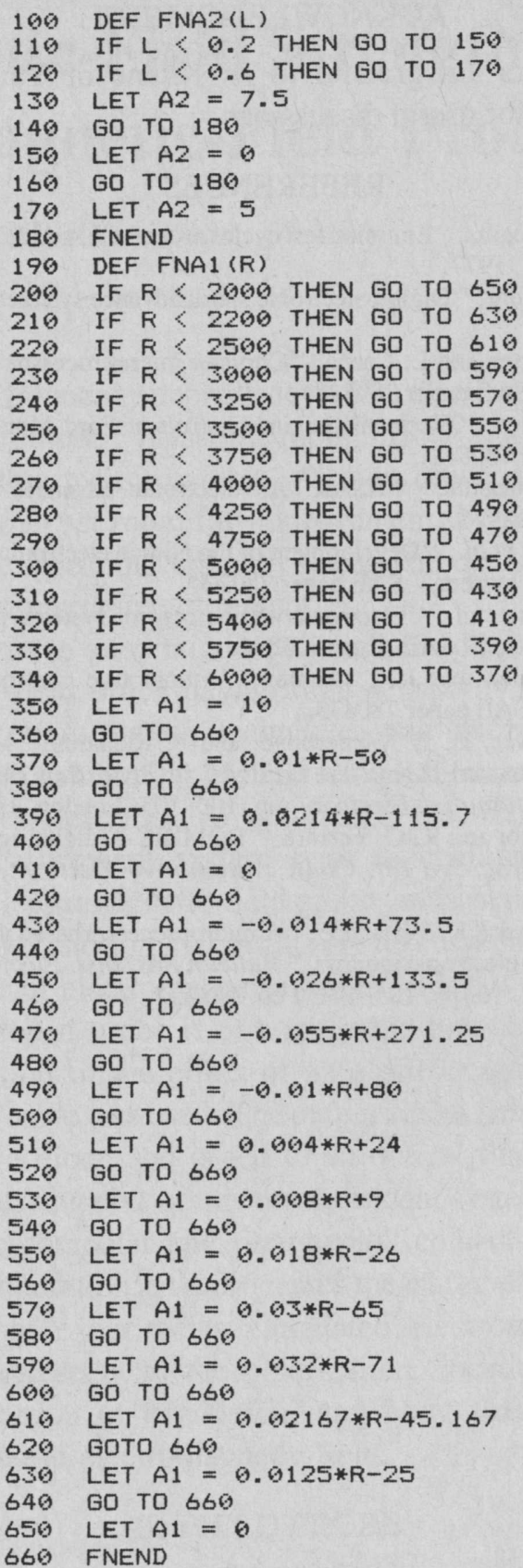

Fig. 10. The function subroutine describing the advance shown in Fig. 8.

mated by the piecewise linear functions given in Fig. 10 and then emulated. The measured results are also shown by circles in Fig. 8, showing the close agreement with the programmed values. The dwell was also measured by the ignitor diagnosis unit. The result has confirmed the satisfactory operation of the calibration system either.

\section{CONCLUSION}

A simple system has been presented for an automotive engine calibration and its capability has been demonstrated by controlling the advances of typical motorcycle engines. This system features the easy operation and the precise calibration. In addition, it allows quick calibration because the engine performance under the idle, accelerating, cruising, and decelerating states can be tested continuously.

This system has been developed for bench calibration. The extension to the on-vehicle calibration system is possible by incorporating the hardware circuitry into the controller unit which modifies the advance data according to the manifold pressure. 


\section{ACKNOWLEDGMENT}

The authors are grateful to A. Kitano of Yamaha Motor Corporation for useful discussions.

\section{REFERENCES}

[1] D. J. Simanaitis, "Emission test cycles around the world,'” Automotive Eng., Aug. 1977.

[2] M. Hansjoerg, "Digital electronic spark advance systems," SAE paper 760265 .

[3] J. Lappington and L. Caron, "Chrysler microprocessor spark advance control," SAE paper 780117.

[4] D. F. Hagen, "Electronic engine controls at Ford Motor Company," SAE paper 780842 .

[5] D. J. Simanaitis, "MISAR: An electronic advance," Automotive Eng., Jan. 1977.

[6] K. Masaki et al., "Development of the Nissan electronically controlled carburetor system," SAE paper 780204.

[7] T. Toyoda et al., "Electronic engine control systems for the smaller passenger car," SAE paper 800894.

[8] T. R. Schlax and J. T. Auman, "Automotive control development system,"' SAE paper 780433.

[9] E. T. Power, D. E. Winterbone, and P. Richards," Microprocessor based automated engine test facility,"' in Proc. 2nd Inst. Elec. Eng. Conf. A utomotive Electron., pp. 100-103, London, 1979.

[10] A. B. Robbi and R. C. Ferrara, "ROMBIC-A digital ignition controller," in Proc. 3rd Int. Conf. Automotive Electron., pp. 179-184, 1981.

[11] M. Tümer and K. Watanabe, "A microprocessorbased diagnosis-based system for electronic ignitors,'” Bulletin Res. Inst. Electron., Shizuoka Univ., vol. 16, pp. 135-141, Feb. 1982.
[12] K. Watanabe, M. Tümer, and A. Kitano, "High precision spark-timing measuring instruments," Internal Combustion Engine, vol. 21, pp. 20-24, May 1982.

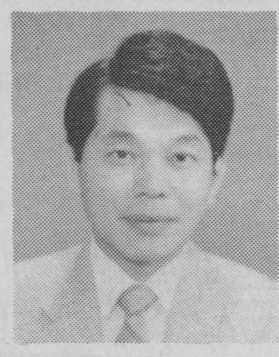

Kenzo Watanabe (M'74) received the B. Eng. and M. Eng. degrees from Shizuoka University, Hamamatsu, Japan, in 1962 and 1966, respectively, and the Dr. Eng. degree from Kyoto University, Kyoto, Japan, in 1976.

From 1966 to 1976, he was a Research Associate at the Research Institute of Electronics, Shizuok University, and since 1977, he has been an Associate Professor. His current research interests are in the areas of electronic engine control and analog signal circuits. processing using active-RC and switched-capacitor

Dr. Watanabe is a member of the Institute of Electronics and Communications Engineers of Japan and the Japan Society of Applied Physics.

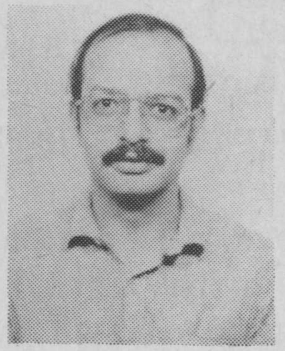

Mehmet Tümer received the B. Eng. degree from Middle East Technical University, Ankara, Turkey, in 1978 and the M. Eng. degree from Shizuoka University, Hamamatsu, Japan, in 1982.

Since 1982, he has been with MEGA Corporation, Ankara, Turkey, where he is responsible for the development of microprocessor-controlled telex system. 